ARTIGO

\title{
Avaliação de desempenho para o apoio à gestão de unidades organizacionais em Ifes: análise e oportunidades
}

\author{
Tatiane Roldão Bastos ${ }^{a}$ \\ André Andrade Longaray ${ }^{b}$ \\ Aléssio Bessa Sarquis ${ }^{c}$ \\ Vilmar Antonio Gonçalves Tondolo ${ }^{d}$
}

\section{Resumo}

Este estudo explora a literatura da avaliação de desempenho para o apoio à gestão de unidades organizacionais de universidades públicas, identificando oportunidades de futuras pesquisas. Neste contexto, foi realizada a revisão sistemática da literatura através do instrumento Knowledge Development Process - Constructivist. Foi selecionado o Portfólio Bibliográfico de artigos cientificamente relevantes, disponíveis e alinhados ao tema de pesquisa, sendo posteriormente realizadas as análises bibliométrica e sistêmica. Ao final deste processo, identifica-se como lacuna de pesquisa a construção de um modelo de avaliação de desempenho que apoie a gestão de unidades organizacionais de universidades públicas, utilizando a abordagem construtivista, conduzindo à construção de conhecimento no decisor, utilizando escalas ordinais e cardinais, realizando a integração dos indicadores a partir dos conhecimentos do decisor e apresentando níveis de referência, permitindo ações de melhoria.

Palavras-chave: Avaliação de Desempenho. Universidade Pública. Revisão Sistemática da Literatura. ProKnow-C.

\section{Introdução}

O presente artigo consiste na Revisão Sistemática da Literatura sobre avaliação de desempenho para o apoio à gestão de Unidades Organizacionais (UO) de

\footnotetext{
a Universidade Federal do Rio Grande, Rio Grande, RS, Brasil.

b Universidade Federal do Rio Grande, Rio Grande, RS, Brasil.

c Universidade do Sul de Santa Catarina, Florianópolis, SC, Brasil.

d Universidade Federal de Pelotas, Pelotas, RS, Brasil.
} 
Instituições Federais de Ensino Superior (Ifes), realizada através de uma ferramenta estruturada, a fim de explicitar o estado da arte. Para isto, foi selecionado um portfólio bibliográfico de artigos alinhados ao tema de pesquisa e realizadas as análises bibliográfica e sistêmica.

A pesquisa se deu devido ao contexto complexo e incerto da gestão pública das Ifes. Considerando-se que os recursos públicos, necessários para a implantação de políticas públicas e para a manutenção das organizações, são limitados e escassos, para otimizar a utilização do erário, ações orientadas à maximização do capital humano é um dos aspectos importantes para a administração pública.

Segundo o Painel Estatístico de Pessoal do Ministério do Planejamento, Desenvolvimento e Gestão (PEP-MPDG) (BRASIL, 2020), os gastos com pessoal do Poder Executivo Federal em fevereiro de 2020 ultrapassaram 20 bilhões de reais, dos quais cerca de $55 \%$ correspondem aos gastos com servidores ativos. Ao redor de $20 \%$ deste valor correspondem aos gastos com servidores vinculados ao Ministério da Educação.

Considerando-se que, dos 1.270.406 servidores do Executivo Federal, 86.415 são professores ativos permanentes do magistério superior e 136.845 são Técnicos Administrativos em Educação ativos (BRASIL, 2020), percebe-se a importância do aperfeiçoamento e da avaliação desta força de trabalho. Nessa perspectiva, a avaliação de desempenho consiste em uma ferramenta de gestão que permite identificar as fragilidades que precisam de melhorias e prever os impactos das ações.

Assim, para compreender como a avaliação de desempenho tem sido utilizada, surge a seguinte questão: Qual o Estado da Arte e as lacunas de pesquisa sobre a temática da avaliação de desempenho como instrumento de apoio à gestão de UO de Ifes? O objetivo é revisar a literatura sobre a temática, desenvolvendo o conhecimento dos pesquisadores sobre o tópico estudado e identificando as oportunidades de pesquisas futuras. Para isso, utilizou-se o instrumento Knowledge Development Process - Constructivim (ProKnow-C), que consiste em um processo estruturado para a Revisão Sistemática da Literatura.

Este trabalho justifica-se, conforme Roesch (2005), quanto à importância, à oportunidade e à viabilidade. Quanto à importância, justifica-se por sua contribuição teórica à comunidade científica ao apresentar as evidências sobre a avaliação de desempenho para o apoio à gestão de UO de Ifes através do desenvolvimento de todas as etapas do ProKnow-C. O estudo é oportuno devido à relevância do tema na atual conjuntura econômico-financeira do país. O estudo é viável 
pela facilidade com que os dados podem ser obtidos a partir dos periódicos indexados pela Plataforma da Coordenação de Aperfeiçoamento de Pessoal de Nível Superior (Capes).

Este artigo é composto por esta seção introdutória, seguida pelo referencial teórico, apresentado na segunda seção, após é discutida a metodologia, na terceira seção, posteriormente, na quarta seção são apresentados os resultados, seguida das considerações finais, tratadas na quinta seção, e ao final são apresentadas as referências.

\section{Avaliação de Desempenho em Universidades Públicas}

A partir de 1930, várias reformas foram desenvolvidas com o intuito de modernizar a administração pública e reduzir os reflexos do patrimonialismo (FILGUEIRAS, 2009). A Revolução Industrial originou ideias sobre uma administração pública otimizada (MOTTA, 2013). E o aumento da demanda por serviços públicos mais eficientes, ocasionado pela complexidade das sociedades, globalização e evolução tecnológica, fortaleceu os esforços para a desburocratização (FAVERO, 2010).

Neste sentido, a Nova Gestão Pública deu origem à utilização de técnicas do setor privado pelo público, visando o aumento da eficiência na prestação de serviços e a redução de custos (MOTTA, 2013). Assim, introduziu-se a avaliação de desempenho no setor público, viabilizando a maximização das atividades de coordenação, controle e aperfeiçoamento da gestão (ARAÚJO; PINHEIRO, 2010). Para isso, são utilizados os indicadores de desempenho, que permitem mensurar os dados organizacionais, orientando a tomada de decisões (ANDRIOLA; ARAÚJO, 2018).

Entretanto, a modernização administrativa do Estado, diferentemente de outros países, ocorre em um contexto socialmente atrasado e marcado por desigualdades em nível nacional e regional (ALMEIDA et al., 2016). Para Abrucio (2007), embora Bresser-Pereira, ministro do governo de Fernando Henrique Cardoso, tenha sido pioneiro em perceber as mudanças da administração pública mundial, também necessárias no Brasil, nem sempre soube traduzi-las politicamente à realidade brasileira.

Para atender aos anseios da sociedade globalizada, assegurando aspectos importantes da Administração Pública, como o combate à corrupção e ao nepotismo, a NGP no Brasil deve tratar-se de um movimento dialético, com a combinação de aspectos weberianos e de novos mecanismos de gestão (ABRUCIO, 2007). Com 
isso, verifica-se a importância da adoção de práticas administrativas com cautela e adaptadas às particularidades não apenas do setor público, como também das características socioeconômicas do país.

Com a corrente da NGP, tornou-se comum também a reforma dos sistemas educacionais, buscando-se o controle dos gastos e a eficiência na prestação de serviços (ARAÚJO; PINHEIRO, 2010). Multiplicaram-se então os desafios das universidades, que além de ofertar Ensino de qualidade, desenvolver pesquisa básica, aplicada e tecnológica, potencializando o conhecimento científico para a resolução de problemas sociais, econômicos, políticos e culturais (MARRA; MELO, 2005), tiveram de lidar com o aumento do número de vagas sem proporcional destinação orçamentária (SANTOS, 2002).

Em resposta a estes desafios, a avaliação de desempenho compreende uma importante ferramenta, viabilizando a melhoria da qualidade dos serviços e motivando uma imagem positiva perante a sociedade (GUERRA; BRITO; SOARES, 2017). Neste sentido, Andriola e Araújo (2018) destacam a necessidade das Ifes por um conjunto confiável de indicadores que auxiliem à tomada de decisões.

Neste tocante, pode-se considerar que a administração universitária, por sua complexidade, está alinhada às Metodologias Multicritério, que partem da concepção de que existem várias pessoas envolvidas no processo decisório, com percepções diferentes do problema que nem sempre é claramente definido e estruturado (ENSSLIN; DUTRA; ENSSLIN, 2000).

O paradigma científico construtivista adotado no apoio à decisão revelou a nova perspectiva da avaliação de desempenho como um instrumento de apoio à decisão (TASCA, 2013). No âmbito das Ifes, percebe-se o alinhamento da metodologia multicritério construtivista como instrumento de apoio à decisão para contextos específicos, permitindo a construção de modelos personalizados a cada setor, de acordo com suas particularidades e considerando as preferências dos gestores das unidades (VALMORBIDA, 2012).

\section{Metodologia}

\subsection{Delineamento da pesquisa}

Quanto ao delineamento, a pesquisa é classificada como descritiva, pois descreve as características dos artigos do Portfólio Bibliográfico (PB), e exploratória, pois objetiva gerar conhecimento ao pesquisador a respeito da temática de estudo, 
de acordo com as restrições adotadas nas buscas nos bancos de dados, com o propósito de evidenciar as oportunidades de pesquisa (ROESCH, 2005).

Quanto às técnicas de coleta, foram utilizados dados secundários, obtidos a partir da seleção de artigos através de periódicos indexados na Plataforma Capes. Quanto às técnicas de análise, classifica-se como qualitativa nas etapas de seleção dos artigos e análise sisêmica, que consiste na análise de conteúdo, e quantitativa na etapa da análise bibliométrica, pois se utiliza técnicas de contagem com o objetivo de evidenciar as principais características dos artigos do PB (ROESCH, 2005).

\subsection{Knowledge Development Process - Constructivism (ProKnow-C)}

Ao iniciar um trabalho científico, o pesquisador precisa ter como ponto de partida o entendimento existente acerca do tópico de interesse, a fim de evidenciar o estado da arte e direcionar a construção de novas percepções (SANTOS; ELIEL; ELIEL, 2006). No entanto, o conhecimento científico encontra-se disperso em uma vasta gama de publicações, bases de dados e outras fontes (TASCA et al., 2010).

Desta forma, para a construção do conhecimento sobre o tema de pesquisa utilizou-se o instrumento de revisão sistemática da literatura denominado Knowledge Development Process - Constructivism (ProKnow-C), que consiste em um processo estruturado para seleção e análise de publicações e que permite ao pesquisador conhecer o desenvolvimento atual da temática estudada, bem como identificar lacunas de pesquisa (ENSSLIN et al., 2015; LUZ et al., 2016).

O Proknow-C é uma ferramenta de pesquisa bibliográfica, desenvolvida no Laboratório de Metodologias Multicritério em Apoio à Decisão (LabMCDA), vinculado ao Departamento de Engenharias de Produção e Sistemas da Universidade Federal de Santa Catarina (ENSSLIN et al., 2015). Através desse processo ordenado, é desenvolvida a seleção do PB de artigos alinhados à temática de interesse e são feitas a análise bibliométrica e a análise sistêmica, fornecendo ao final o estado da arte do tema de pesquisa, conforme a Figura 1.

A seleção do PB é a reunião de artigos alinhados ao tema de pesquisa, selecionados a partir de um conjunto de delimitações e de acordo com a percepção do pesquisador. Na segunda etapa, o PB é analisado quantitativamente, dando embasamento aos pesquisadores sobre onde e como buscar informações sobre o tema. Posteriormente, o PB é analisado qualitativamente, através de lentes que explicitam a afiliação teórica adotada pelo pesquisador, complementando o 
conhecimento sobre a temática e emergindo ao final do processo os destaques e as lacunas de pesquisa.

Figura 1 - Etapas do ProKnow-C

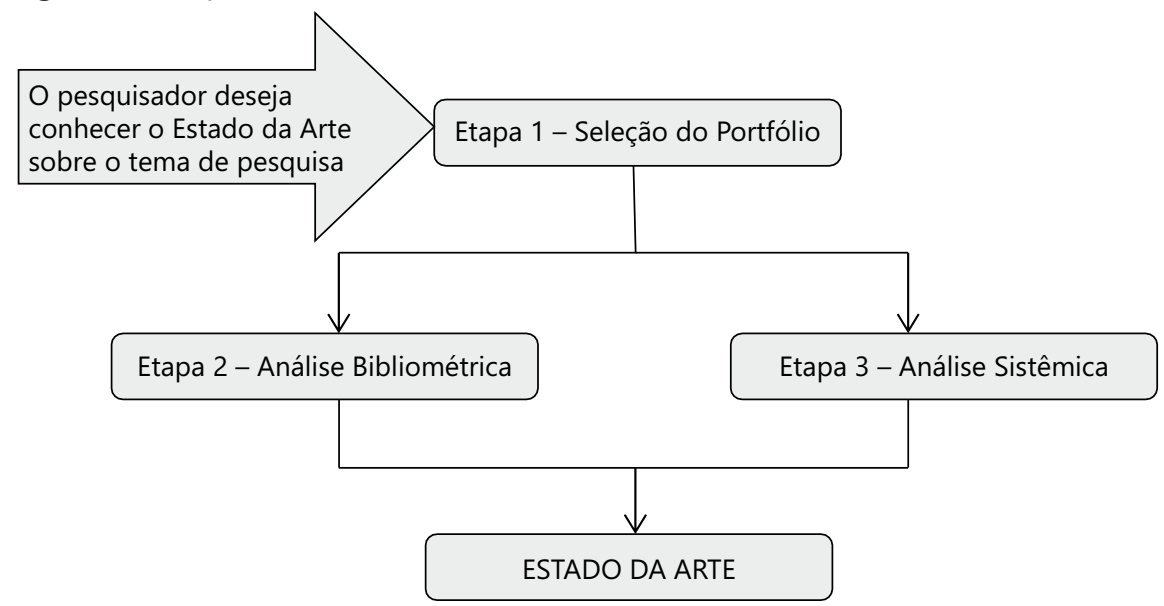

Fonte: Adaptado de Dutra et al. (2015)

\section{Resultados}

\subsection{Seleção do portfólio bibliográfico}

$\mathrm{O} \mathrm{PB}$ consiste no conjunto de artigos alinhados à temática da pesquisa, com reconhecimento científico e disponíveis para acesso gratuito. Trata-se de um recorte, visto a impossibilidade de se analisar a totalidade de produções. Este recorte não equivale a uma amostra representativa do universo de publicações, mas sim ao grupamento de artigos considerados mais relevantes, de acordo com os mecanismos de busca e a percepção do pesquisador. Para a formação deste portfólio, realizou-se a seleção do banco de artigos brutos, as filtragens e o teste de representatividade.

O banco de artigos brutos equivale ao fragmento da literatura resultante da pesquisa de todas as combinações possíveis de palavras-chave determinadas na estratégia de busca, em todas as bases de dados escolhidas para a pesquisa. O Quadro 1 apresenta a estratégia de busca utilizada para a pesquisa nas bases de dados. Optou-se por utilizar seis bases de dados indexadas pela Plataforma CAPES que agregam pesquisas das áreas de ciências sociais aplicadas: Wiley, EBSCO, Emerald, ProQuest, Scopus e Web of Science. 
Quadro 1 - Estratégia de busca

\begin{tabular}{|c|c|c|c|}
\hline $\begin{array}{l}\text { Eixo } \\
\text { Temático }\end{array}$ & \multicolumn{3}{|c|}{$\begin{array}{l}\text { Avaliação de desempenho como instrumento de apoio à gestão de } \\
\text { unidades organizacionais de universidade pública }\end{array}$} \\
\hline \multirow{6}{*}{ 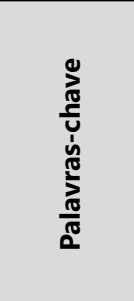 } & $\begin{array}{l}\text { Eixo 1: Avaliação de } \\
\text { desempenho }\end{array}$ & $\begin{array}{l}\text { Eixo 2: Gestão de UO em } \\
\text { universidade pública }\end{array}$ & Eixo 3: Setor público \\
\hline & performance evaluation & organizational unit & public university \\
\hline & performance assessment & administrative unit & government \\
\hline & Performance measurement & university administration & college \\
\hline & \multirow{2}{*}{ performance appraisal } & university staff & undergraduate \\
\hline & & academic staff & higher education \\
\hline
\end{tabular}

Fonte: Elaboração dos autores (2018)

Foram pesquisados artigos publicados até março de 2020, retornando o montante de 13.969 artigos, que foram importados para o software de gerenciamento bibliográfico EndNote, formando o banco de artigos brutos. Com o banco de artigos brutos composto, procederam-se as filtragens dos artigos quanto à redundância, ao alinhamento do título ao tema de pesquisa, ao alinhamento do resumo e palavras-chave, à disponibilidade, ao reconhecimento científico e ao alinhamento do texto completo, conforme o fluxograma apresentado na Figura 2.

Figura 2 - Filtragens dos artigos brutos

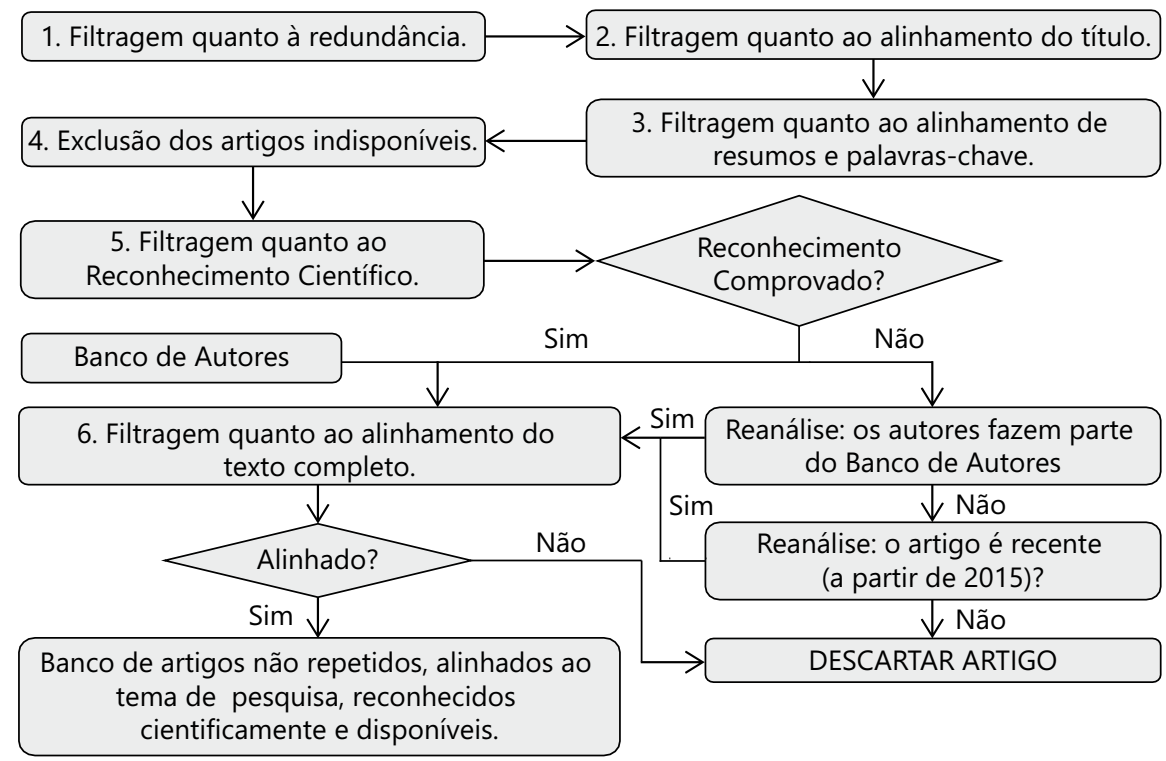

Fonte: Adaptado de Dutra et al. (2015) 
$\mathrm{Na}$ primeira filtragem, foram excluídos os artigos repetidos, resultando 3.141 trabalhos não duplicados. Na segunda filtragem, na qual realizou-se a leitura dos títulos, 314 artigos apresentaram-se em conformidade com o tema de pesquisa.

$\mathrm{Na}$ terceira filtragem, procedeu-se a leitura dos resumos e palavras-chave, chegando-se a 128 artigos alinhados à temática do estudo. Na quarta filtragem foram excluídos os trabalhos que não tinham acesso gratuito ao texto completo, atingindo o montante de 58 artigos disponíveis.

Após, realizou-se a quinta filtragem, quanto ao reconhecimento científico das pesquisas. Inicialmente, consultou-se o número de citações dos 58 artigos no Google Acadêmico, totalizando 1.743 citações. Os trabalhos foram organizados em ordem decrescente do número de citações e, realizando-se o cálculo do percentual acumulado, se estabeleceu como ponto de corte $90 \%$ do total de citações.

Desta forma, foi definido que teriam reconhecimento científico comprovado, os artigos com 25 citações ou mais. Desta análise resultaram 19 artigos com reconhecimento científico comprovado, compondo então um banco de autores.

Os demais artigos passaram pela reanálise. Primeiramente, foi observado se os autores dos trabalhos constavam no banco de autores. Posteriormente, foi verificado se as publicações eram recentes, ou seja, a partir de 2015.

Após a reanálise, 42 pesquisas foram reconhecidas cientificamente, passando então pela sexta filtragem, na qual se realizou a leitura dos textos completos, resultando 17 artigos não repetidos, disponíveis, alinhados ao tema de pesquisa e reconhecidos cientificamente.

Para se certificar de que não houve publicações em consonância com o tema e com reconhecimento científico não incluídas no $\mathrm{PB}$, foi realizado o teste de representatividade. Assim, todos os artigos constantes nas referências bibliográficas dos 17 trabalhos selecionados foram importados para o EndNote e foram realizadas as filtragens.

Ao final desta análise, foi incluído ao PB um novo trabalho alinhado ao tema. Desta forma, o PB final ficou composto por 18 artigos (Quadro 2). 
Quadro 2 - Portfólio bibliográfico

\begin{tabular}{|c|c|c|}
\hline Ano & Autores & Título \\
\hline 2015 & $\begin{array}{l}\text { Özdemir } \\
\text { Tüysüz }\end{array}$ & $\begin{array}{l}\text { An Integrated Fuzzy DEMATEL and Fuzzy ANP Based } \\
\text { Balanced Scorecard Approach: Application in Turkish Higher } \\
\text { Education Institutions }\end{array}$ \\
\hline 2002 & $\begin{array}{l}\text { Moreno } \\
\text { Tadepalli }\end{array}$ & Assessing Academic Department Efficiency at a Public University \\
\hline 2013 & $\begin{array}{l}\text { Umashankar } \\
\text { Dutta }\end{array}$ & $\begin{array}{l}\text { Balanced scorecards in managing higher education institutions: } \\
\text { an Indian perspective }\end{array}$ \\
\hline 2015 & $\begin{array}{l}\text { Placek Ochrana } \\
\text { Pucek }\end{array}$ & $\begin{array}{l}\text { Benchmarking in Czech higher education: the case of schools } \\
\text { of economics }\end{array}$ \\
\hline 2014 & $\begin{array}{l}\text { Agasisti } \\
\text { Bonomi }\end{array}$ & $\begin{array}{l}\text { Benchmarking universities' efficiency indicators in the presence of } \\
\text { internal heterogeneity }\end{array}$ \\
\hline 2009 & Agasisti Johnes & $\begin{array}{l}\text { Beyond frontiers: comparing the efficiency of higher education } \\
\text { decision-making units across more than one country }\end{array}$ \\
\hline 2005 & $\begin{array}{l}\text { Rosa Saraiva } \\
\text { Diz }\end{array}$ & $\begin{array}{l}\text { Defining Strategic and Excellence Bases for the Development of } \\
\text { Portuguese Higher Education }\end{array}$ \\
\hline 2015 & Agasisti Johnes & $\begin{array}{l}\text { Efficiency, costs, rankings and heterogeneity: the case of US } \\
\text { higher education }\end{array}$ \\
\hline 2018 & Yousif Shaout & $\begin{array}{l}\text { Fuzzy logic computational model for performance evaluation of } \\
\text { Sudanese Universities and academic staff }\end{array}$ \\
\hline 2014 & $\begin{array}{l}\text { McCormack } \\
\text { Propper Smith }\end{array}$ & $\begin{array}{l}\text { HERDING CATS? MANAGEMENT AND UNIVERSITY } \\
\text { PERFORMANCE* }\end{array}$ \\
\hline 2015 & $\begin{array}{l}\text { Pereira Pereira } \\
\text { Monteiro }\end{array}$ & $\begin{array}{l}\text { Mapeamento conceitual do Balanced Scorecard no } \\
\text { ensino superior }\end{array}$ \\
\hline 2018 & $\begin{array}{l}\text { Zuniga-Jara } \\
\text { et al }\end{array}$ & Midiendo la Creación de Valor en una Universidad \\
\hline 2017 & $\begin{array}{l}\text { Machorro } \\
\text { Romero }\end{array}$ & $\begin{array}{l}\text { Propuesta de un Instrumento de Autoevaluación del Desempeño } \\
\text { Organizacional en Instituciones Públicas de Educación Superior } \\
\text { en México }\end{array}$ \\
\hline 2018 & Dobija et al & $\begin{array}{l}\text { Rational and symbolic uses of performance measurement } \\
\text { Experiences from Polish universities }\end{array}$ \\
\hline 2020 & Kuzu & $\begin{array}{l}\text { Strategy selection in the universities via fuzzy AHP method: } \\
\text { A case study }\end{array}$ \\
\hline 2002 & $\begin{array}{l}\text { Mollis } \\
\text { Marginson }\end{array}$ & $\begin{array}{l}\text { The assessment of universities in Argentina and Australia: } \\
\text { between autonomy and heteronomy }\end{array}$ \\
\hline 2006 & Abdullah & $\begin{array}{l}\text { The development of HEdPERF: a new measuring instrument of } \\
\text { service quality for the higher education sector }\end{array}$ \\
\hline 2006 & Köksal Nalçaci & $\begin{array}{l}\text { The Relative Efficiency of Departments at a Turkish Engineering } \\
\text { College: A Data Envelopment Analysis }\end{array}$ \\
\hline
\end{tabular}

Fonte: Elaboração dos autores (2018) 


\section{a) Análise bibliométrica}

A bibliometria consiste na ferramenta de gerenciamento da informação, através da quantificação das informações sobre os artigos do PB, com o intuito de gerar conhecimento sobre o tema de pesquisa (ENSSLIN et al., 2015). Assim, foi realizada a análise bibliométrica sob quatro perspectivas: relevância dos periódicos, reconhecimento científico, autores de maior destaque e análise do fator de impacto.

Na primeira dimensão estudada, foi verificada a relevância dos periódicos do $\mathrm{PB}$, através da contagem do número de artigos publicados. Conforme o Quadro 3, depreende-se que Studies in Higher Education, Higher Education e Formación Universitaria foram os periódicos mais relevantes, com dois artigos cada.

Na segunda perspectiva, o reconhecimento científico dos artigos foi obtido a partir do número de citações pesquisadas no Google Acadêmico. Os dados desta análise são demonstrados no Quadro 4. O terceiro aspecto investigado refere-se aos autores de maior destaque. Conforme a Figura 3 observa-se que Agasisti, T. e Johnes, G. são os autores mais relevantes do PB, com três e dois artigos, respectivamente.

Quadro 3 - Relevância dos periódicos do PB

\begin{tabular}{|l|c|}
\hline Periódico & Número de Publicações \\
\hline Higher Education & 2 \\
\hline Studies in Higher Education & 2 \\
\hline Formación Universitaria & 2 \\
\hline Accounting, Auditing \& Accountability Journal & 1 \\
\hline Education Economics & 1 \\
\hline European Journal of Education & 1 \\
\hline International Jounal of Educational Management & 1 \\
\hline International Journal of Consumer Studies & 1 \\
\hline International Journal of Higher Education & 1 \\
\hline Journal of Higher Education Policy and Management & 1 \\
\hline Journal of King Saud University - Computer and Information Science & 1 \\
\hline Journal of Multiple-Valued Logic \& soft computing & 1 \\
\hline Managerial and Decision Economics & 1 \\
\hline Revista Capital Científico & 1 \\
\hline The Economic Journal & 1 \\
\hline
\end{tabular}

Fonte: Elaboração dos autores (2018) 
Figura 3 - Participação dos autores no PB

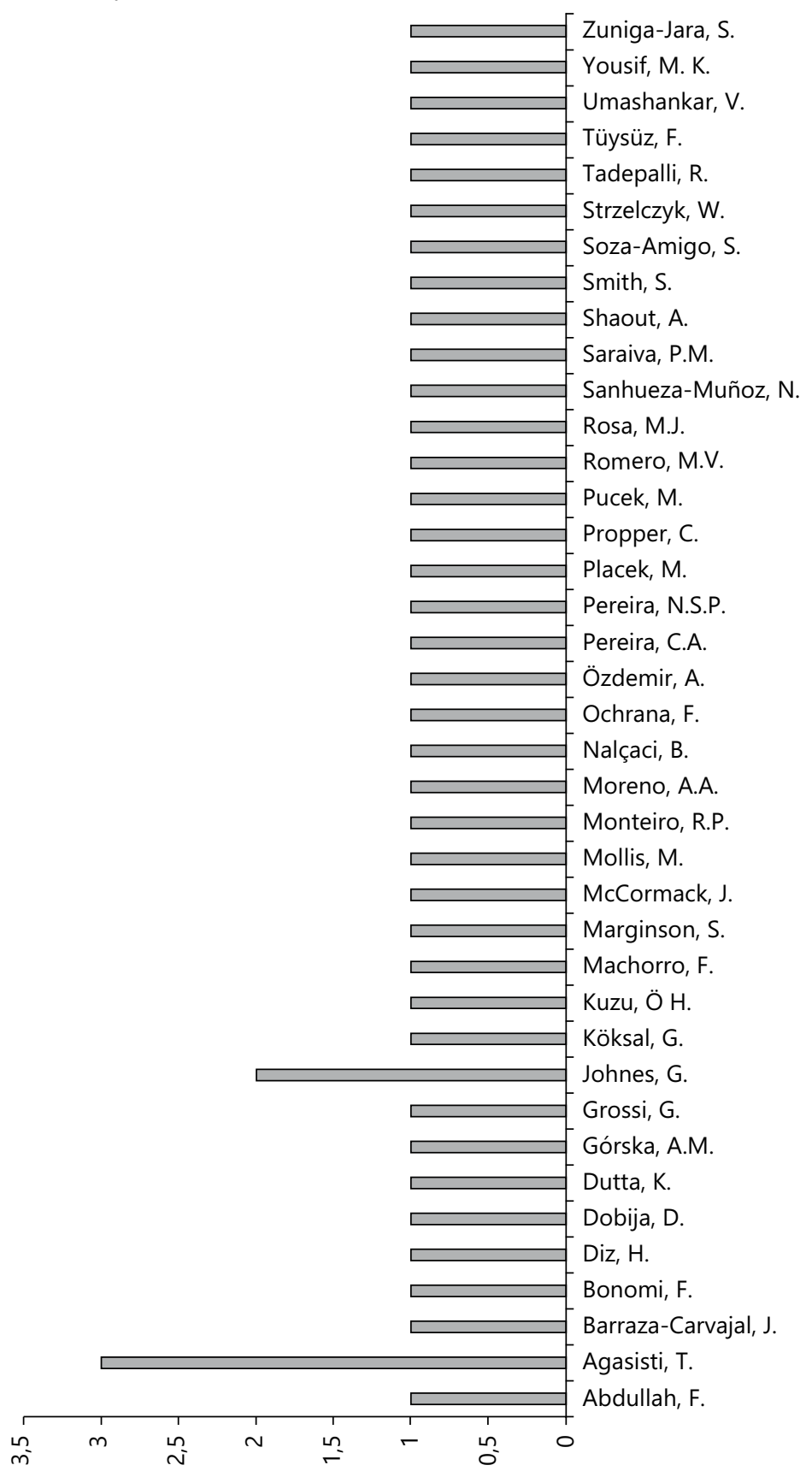

Fonte: Elaboração dos autores (2018) 
Quadro 4 - Reconhecimento Científico dos artigos do PB

\begin{tabular}{|l|c|}
\hline Título & Citações \\
\hline $\begin{array}{l}\text { The development of HEdPERF: a new measuring instrument of service quality for } \\
\text { the higher education sector }\end{array}$ & 337 \\
\hline Balanced scorecards in managing higher education institutions: an Indian perspective & 192 \\
\hline $\begin{array}{l}\text { Beyond frontiers: comparing the efficiency of higher education decision-making } \\
\text { units across more than one country }\end{array}$ & 122 \\
\hline $\begin{array}{l}\text { The assessment os universities in Argentina and Australia: between autonomy } \\
\text { and heteronomy }\end{array}$ & 92 \\
\hline Assessing Academic Department Efficiency at a Public University & 72 \\
\hline $\begin{array}{l}\text { The Relative Efficiency of Departments at a Turkish Engineering College: A Data } \\
\text { Envelopment Analysis }\end{array}$ & 60 \\
\hline Herding cats? Management and university performance & 56 \\
\hline $\begin{array}{l}\text { Benchmarking universities' efficiency indicators in the presence of } \\
\text { internal heterogeneity }\end{array}$ & 29 \\
\hline Efficiency, costs, rankings and heterogeneity: the case of US higher education & 26 \\
\hline $\begin{array}{l}\text { Defining Strategic and Excellence Bases for the Development of Portuguese } \\
\text { Higher Education }\end{array}$ & 25 \\
\hline $\begin{array}{l}\text { Fuzzy logic computational model for performance evaluation of Sudanese } \\
\text { Universities and academic staff }\end{array}$ & 12 \\
\hline $\begin{array}{l}\text { Rational and symbolic uses of performance measurement Experiences from } \\
\text { Polish universities }\end{array}$ & 8 \\
\hline $\begin{array}{l}\text { Propuesta de un Instrumento de Autoevaluación del Desempeño Organizacional } \\
\text { en Instituciones Públicas de Educación Superior en México }\end{array}$ & 3 \\
\hline Benchmarking in Czech higher education: the case of schools of economics \\
\hline $\begin{array}{l}\text { An Integrated Fuzzy DEMATEL and Fuzzy ANP Based Balanced Scorecard } \\
\text { Approach: Application in Turkish Higher Education Institutions }\end{array}$ & 2 \\
\hline Midiendo la Creación de Valor en una Universidad & 0 \\
\hline Mapeamento conceitual do Balanced Scorecard no Ensino Superior & 0 \\
\hline Strategy selection in the universities via fuzzy AHP method: A case study & 1 \\
\hline
\end{tabular}

Fonte: Elaboração dos autores (2018)

Por fim, a quarta investigação refere-se ao fator de impacto dos periódicos do PB. Para este trabalho, foi consultado o fator de impacto dos 15 periódicos do PB nas bases Thomson Reuters, que fornece o indicador JCR (Journal Citation Report) a partir de dados da Web of Science, e SCImago Journal \& Country Rank, que fornece o indicador SJR (Scimago Journal Rank) a partir de informações da plataforma Scopus.

Da análise do JCR, observa-se que os periódicos Higher Education, Studies in Higher Education, Journal of King Saud University - Computer and Information Science e Accounting, Auditing \& Accountability Journal apresentaram os maiores Fatores de Impacto (Figura 4). 
Da análise do SJR, tem-se que o periódico Studies in Higher Education apresentou o maior Fator de Impacto, seguido do Higher Education (Figura 5).

Figura 4 - Fator de Impacto JCR dos periódicos do PB

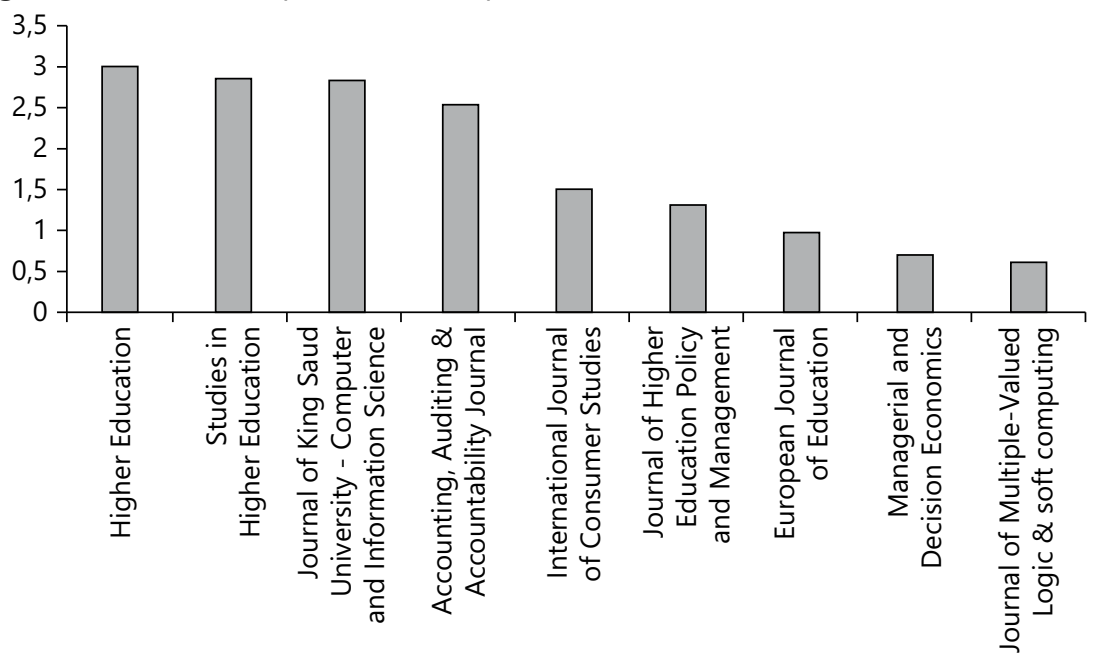

Fonte: Elaboração dos autores (2018)

Figura 5 - Fator de Impacto SJR dos periódicos do PB

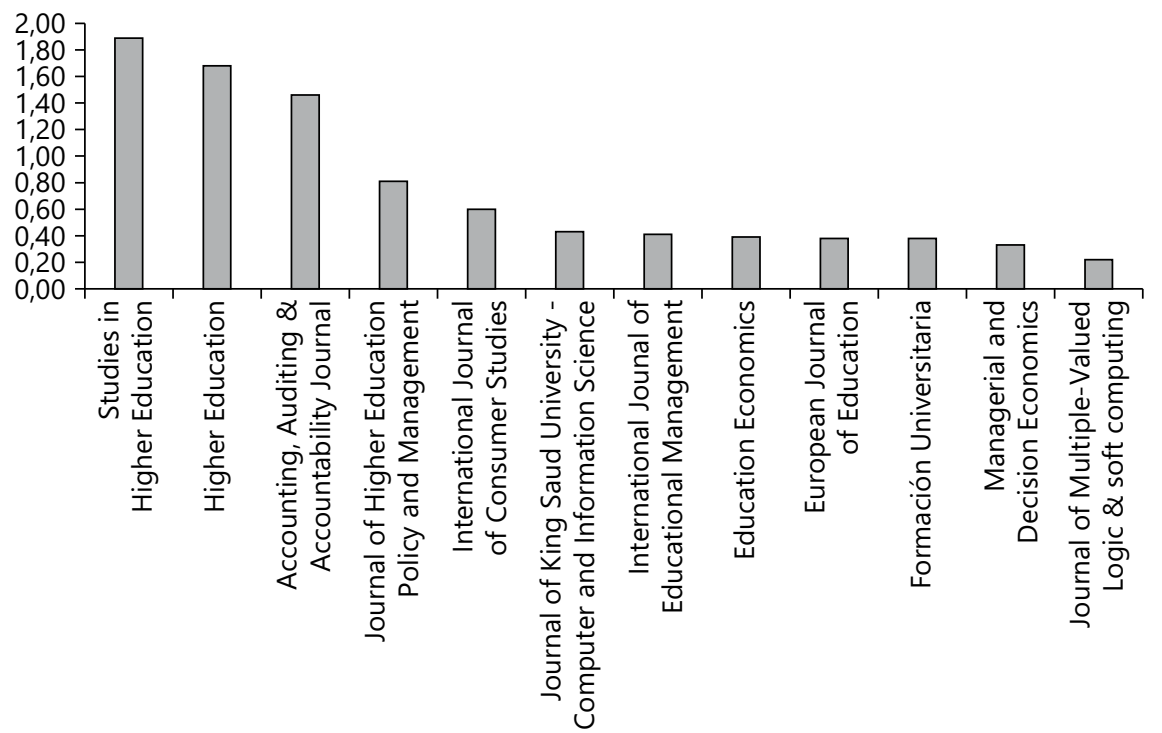

Fonte: Elaboração dos autores (2018) 


\section{b) Análise sistêmica}

$\mathrm{Na}$ análise sistêmica, os artigos que compõem o PB são examinados criticamente através de lentes que explicitam a afiliação teórica do pesquisador, com o intuito de identificar os destaques e as lacunas de pesquisa (TASCA et al., 2010).

No presente trabalho, adotou-se como afiliação teórica o conceito da avaliação de desempenho como processo para construir conhecimento no decisor, a respeito do contexto específico que se propõe avaliar, a partir da percepção do próprio decisor por meio de atividades que identificam, organizam, mensuram ordinalmente e cardinalmente, integram e permitem visualizar o impacto das ações e seu gerenciamento (ENSSLIN et al., 2018). Assim, foram utilizadas as seis lentes apresentadas na Figura 6 e evidenciadas no Quadro 5.

Figura 6 - Lentes da Análise Sistêmica

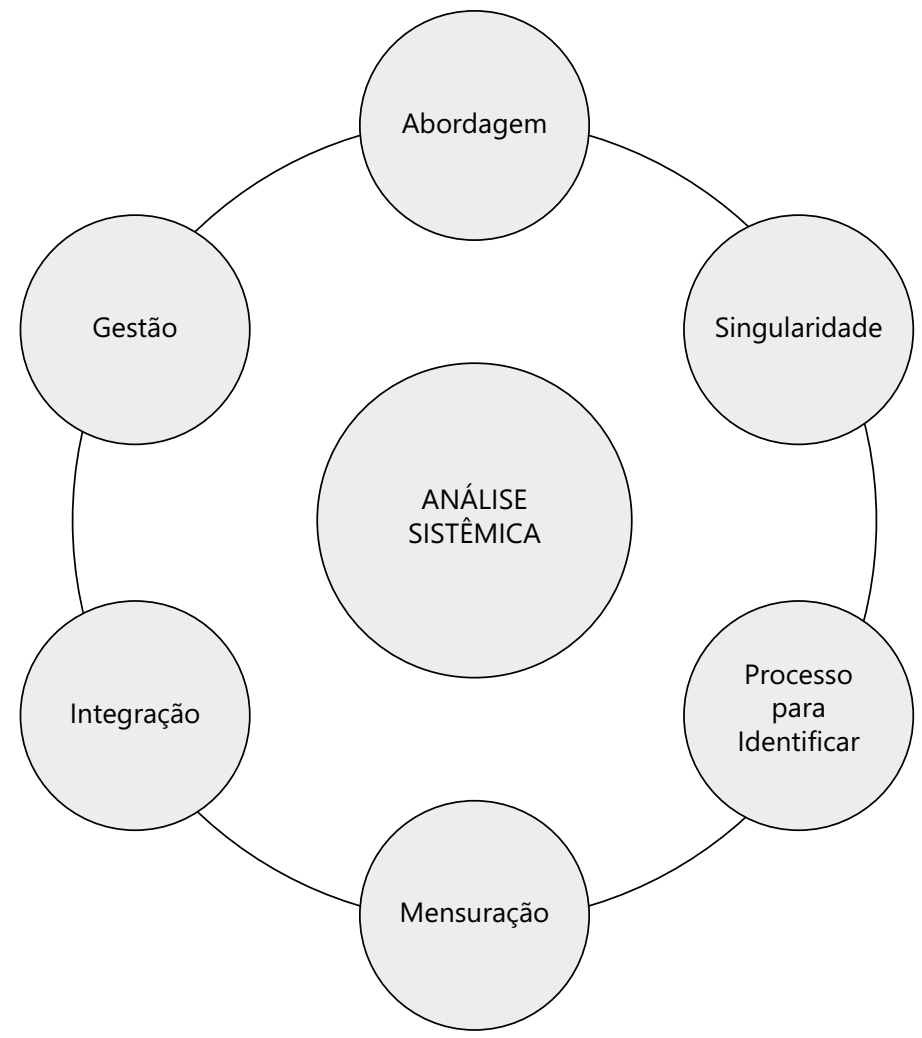

Fonte: Adaptado de Tasca et al. (2010) 
Quadro 5 - Lentes da Análise Sistêmica

\begin{tabular}{|c|l|l|}
\hline \multicolumn{2}{|c|}{ Lente } & \multicolumn{1}{c|}{ O que busca? } \\
\hline 1 & Abordagem & $\begin{array}{l}\text { Há harmonia entre a abordagem utilizada para a construção do } \\
\text { modelo e sua aplicação? }\end{array}$ \\
\hline 2 & Singularidade & $\begin{array}{l}\text { Reconhece que o problema é único quanto ao contexto e } \\
\text { atores envolvidos? }\end{array}$ \\
\hline 3 & $\begin{array}{l}\text { Processos para } \\
\text { identificar }\end{array}$ & $\begin{array}{l}\text { Processo para identificar os critérios/objetivos segundo a percepção } \\
\text { do decisor? }\end{array}$ \\
\hline 6 & Mensuração & $\begin{array}{l}\text { As escalas (descritivas/nominais/ordinais/cardinais) utilizadas } \\
\text { (mendem à Teoria da Mensuração e suas propriedades } \\
\text { inteligibilidade/ distinção entre os desempenhos melhor e pior)? }\end{array}$ \\
\hline 5 & Integração & É realizada a integração dos indicadores em uma avaliação global? \\
\hline 6 & Gestão & $\begin{array}{l}\text { Permite diagnosticar os pontos fortes e fracos da situação atual? } \\
\text { Disponibiliza processo para gerar ações de aperfeiçoamento? }\end{array}$ \\
\hline
\end{tabular}

Fonte: Adaptado de Dutra et al. (2015)

A primeira lente apreciada na análise sistêmica busca responder a seguinte questão: A abordagem utilizada no artigo harmoniza o modelo construído com sua aplicação? Conforme Dutra et al. (2015), a abordagem pode ser classificada conforme quatro categorias: normativista, descritivista, prescritivista e construtivista.

$\mathrm{Na}$ abordagem normativista, guiada pelo racionalismo, o pesquisador seleciona o modelo baseado no conhecimento científico, ou seja, na literatura existente e/ou conhecimentos de especialistas. Na abordagem descritivista, também racionalista, as variáveis para a construção do modelo são identificadas a partir do contexto físico e, de forma limitada e não obrigatória, pelo decisor (TASCA, 2013).

$\mathrm{Na}$ abordagem prescritivista, o decisor consiste na fonte de dados utilizada para a construção do modelo, no entanto a construção do conhecimento ocorre para o facilitador. Por fim, na abordagem construtivista, de forma semelhante ao viés prescritivista, as variáveis que compõem o modelo são obtidas a partir do decisor, no entanto cabe ao facilitador apoiar o decisor nesse processo, em que a expansão do conhecimento ocorre no decisor (TASCA, 2013).

O resultado desta análise é apresentado na Figura 7. Observa-se que houve predominância das abordagens descritivista e normativista pelos autores dos artigos do PB. Em nenhum artigo foi utilizada a abordagem construtivista. 
Figura 7 - Abordagem utilizada para a construção do modelo

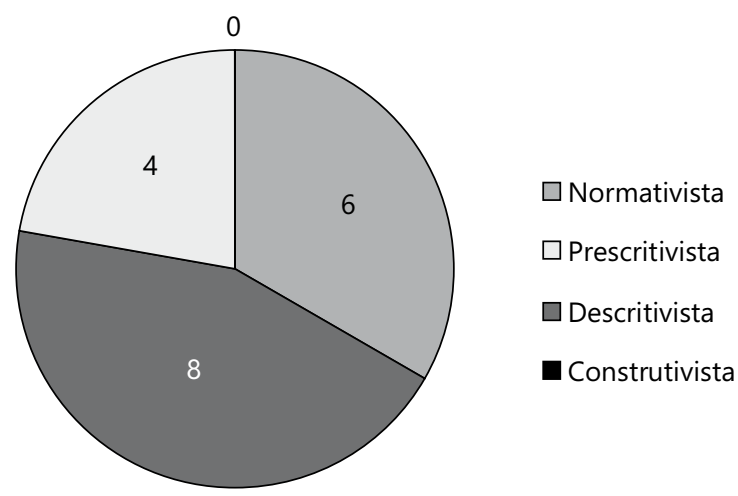

Fonte: Elaboração dos autores (2018)

Quanto ao local onde o modelo foi utilizado, é verificado se o contexto é genérico ou específico, sendo que por específico compreende-se o modelo aplicado a um contexto bem definido. Desta forma, 14 artigos do PB apresentaram-se em contextos genéricos, conforme apresentado na Figura 8.

Figura 8 - Local onde o modelo é aplicado

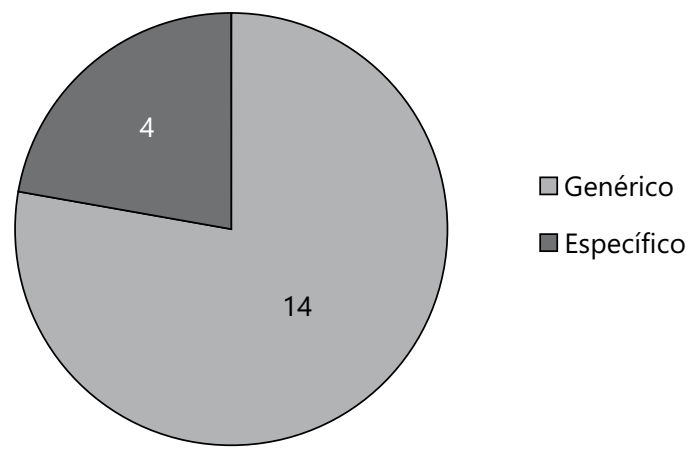

Fonte: Elaboração dos autores (2018)

A análise da harmonia entre a abordagem utilizada para a construção do modelo e sua aplicação foi realizada com base no Quadro 6. Observa-se que ocorre harmonia nos casos A (abordagem realista e uso genérico) e D (abordagem prescritivista ou construtivista e uso específico). 
Quadro 6 - Composições das abordagens e seus usos/aplicações para identificação da harmonia

\begin{tabular}{|c|c|c|c|}
\hline \multicolumn{2}{|c|}{ ABORDAGEM } & USO/APLICAÇÃO & HARMONIA \\
\hline A & $\begin{array}{c}\text { REALISTA } \\
\text { R }\end{array}$ & Genérico & SIM \\
\cline { 1 - 3 } B & Normativista ou Descritivista & Específico & NÃO \\
\cline { 3 - 4 } C & \multirow{2}{*}{ Prescritivista ou Construtivista } & Genérico & NÃO \\
\cline { 1 - 1 } D & & Específico & SIM \\
\hline
\end{tabular}

Fonte: Tasca (2013)

A Figura 9 apresenta o resultado deste exame. Verifica-se que 12 artigos do PB apresentaram harmonia entre a abordagem utilizada e a aplicação do modelo. Da apreciação da primeira lente, é possível inferir a opção majoritária dos autores pelas abordagens realistas, com busca predominantemente no contexto físico e na literatura.

Figura 9 - Análise da harmonia entre a abordagem utilizada para a construção do modelo e seu uso

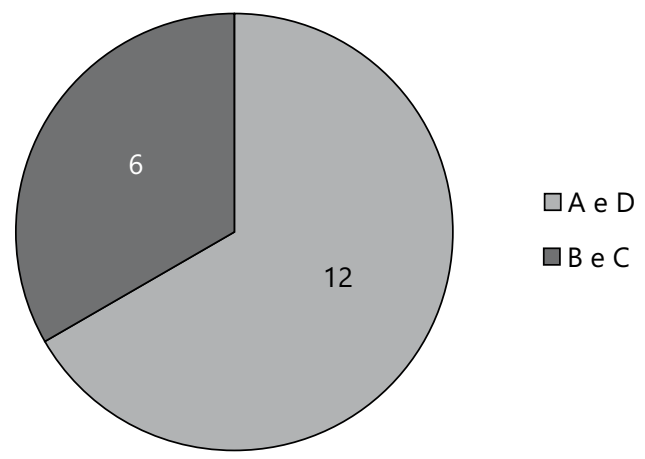

Fonte: Elaboração dos autores (2018)

Na segunda lente, busca-se identificar se o problema abordado no artigo assume caráter único quanto ao contexto físico e atores envolvidos. Quanto aos atores envolvidos, observa-se que seis artigos consideram o decisor para a definição das variáveis que compõem o modelo, porém de forma parcial, e um considera o decisor para a construção integral do modelo. Nos demais artigos a figura do decisor não foi explicitada, conforme apresentado na Figura 10. 
Figura 10 - Participação do decisor no processo de apoio à decisão dos artigos do PB

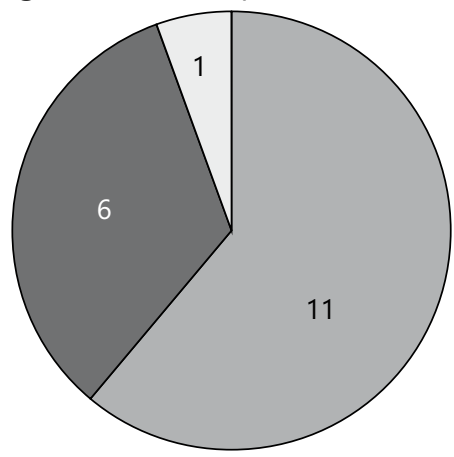

$\square$ Não identifica o decisor no trabalho.

$\square$ Identifica o decisor no trabalho, porém não o considera para a construção integral do modelo.

$\square$ Identifica o decisor no trabalho e o considera para a construção integral do modelo.

Fonte: Elaboração dos autores (2018)

Quanto ao contexto físico, 15 artigos reconhecem que o modelo não pode ser aplicado a outros contextos (Figura 11).

Figura 11 - Artigos do PB que reconhecem o contexto físico como singular

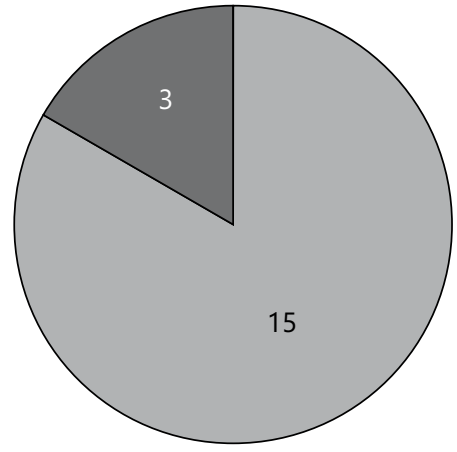

$\square$ Desenvolve o modelo para um contexto físico e reconhece que o modelo é válido apenas para este contexto.

$\square$ Desenvolve o modelo para um contexto físico entendendo que pode ser aplicado a outros.

Fonte: Elaboração dos autores (2018)

O processo para identificação dos objetivos refere-se à necessidade de se incorporar ao modelo de avaliação os valores, as percepções e as preferências do decisor. Neste contexto, a terceira lente da análise sistêmica busca responder a seguinte questão: Como os autores dos artigos do PB identificam os objetivos segundo a percepção do decisor?

Esta análise é realizada em duas etapas. A primeira visa observar se o artigo reconhece a necessidade de expansão de conhecimento no decisor, enquanto na segunda, observa-se como os valores e preferências do decisor interferem na 
identificação dos objetivos. Da primeira análise, apresentada na Figura 12, constatase que em nenhum artigo houve a preocupação de gerar conhecimento no decisor.

Figura 12 - Reconhecimento dos limites de conhecimento do decisor

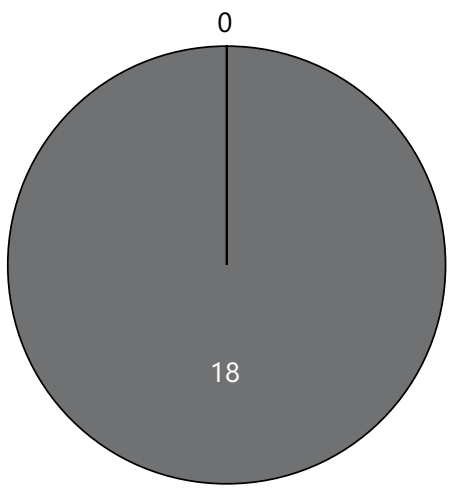

$\square$ Reconhece a necessidade de expansão de conhecimento no decisor.

$\square$ Não reconhece a necessidade de expansão de conhecimento no decisor.

Fonte: Elaboração os autores (2018)

Em relação à segunda questão examinada, sete artigos consideram a percepção do decisor, porém apenas um o considera integralmente (Figura 13).

Figura 13 - Processo considera os valores do decisor

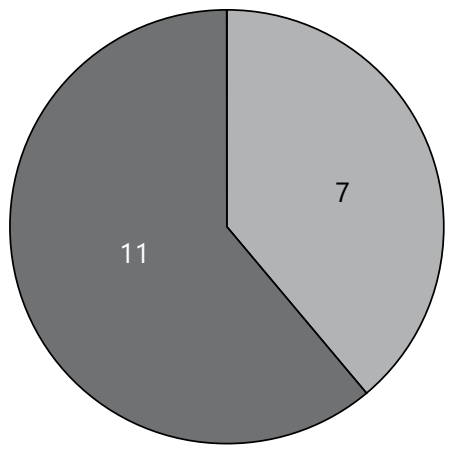

$\square$ Considera os valores do decisor.

$\square$ Não considera os valores do decisor.

Fonte: Elaboração dos autores (2018)

$\mathrm{Na}$ quarta lente, o objetivo é identificar se as escalas (descritivas, nominais, ordinais ou cardinais) atendem à Teoria da Mensuração e suas propriedades (mensurabilidade, operacionalidade, homogeneidade, inteligibilidade e distinção entre os desempenhos melhor e pior). Assim, desta análise tem-se que oito artigos atendem às propriedades da Teoria da Mensuração (Figura 14). 
Figura 14 - Artigos do PB nos quais as escalas atendem às propriedades de mensurabilidade, operacionalidade, homogeneidade, inteligibilidade e permitir distinguir entre melhor e pior

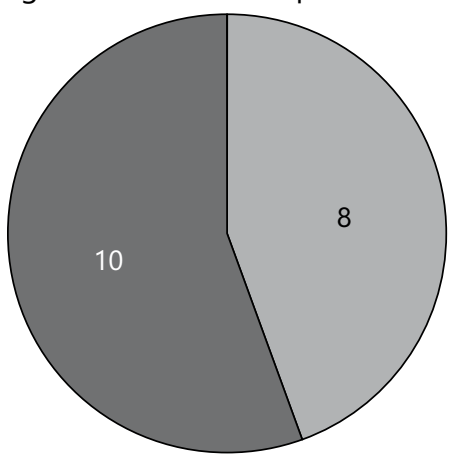

$\square$ Atendem às propriedades da Teoria da Mensuração.

Não atendem às escalas da

Teoria da Mensuração.

Fonte: Elaboração dos autores (2018)

Em relação às operações estatísticas utilizadas, sete artigos atendem à Teoria da Mensuração (Figura 15).

Figura 15 - Artigos do PB nos quais as escalas atendem à Teoria da Mensuração

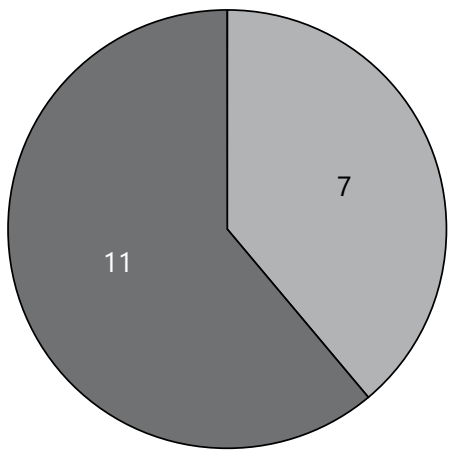

$\square$ Atendem à Teoria da Mensuração.

Não atendem à Teoria da Mensuração.

Fonte: Elaboração dos autores (2018)

A quinta lente refere-se à integração dos critérios de avaliação de desempenho, permitindo a realização da avaliação global do contexto estudado. Conforme Valmorbida (2012), a integração de escalas pode ser realizada de forma descritiva, gráfica, cardinal utilizando níveis de referência ou cardinal sem utilização de níveis de referência, em que por nível de referência compreendem-se níveis que permitem identificar quais ações são mais atrativas e quais apresentam desempenho 
inferior ao esperado. Conclui-se desta análise que em 14 artigos a integração dos indicadores é realizada, porém sem apresentar níveis de referência (Figura 16).

Figura 16 - Artigos do PB que realizam a integração dos indicadores

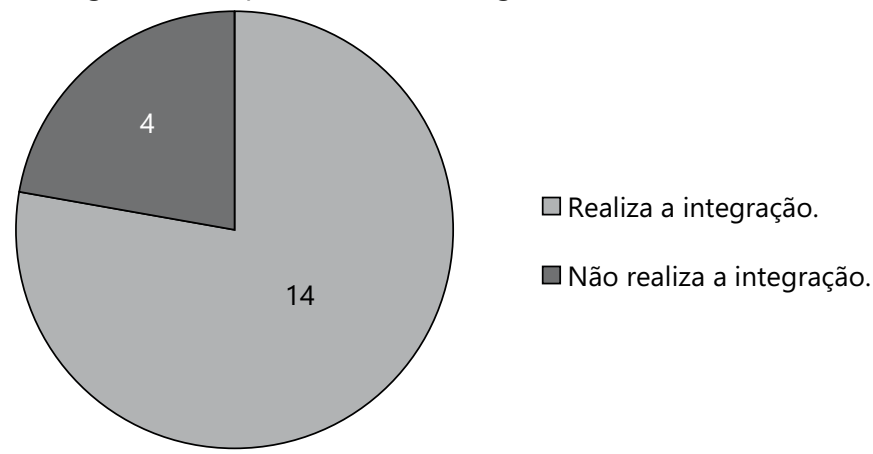

Fonte: Elaboração dos autores (2018)

Na sexta e última lente, os artigos do PB são examinados quanto ao processo de gestão. É analisado se o sistema de avaliação de desempenho permite conhecer a situação atual, realizar o monitoramento e gerar ações de melhorias. Neste sentido, é realizada a análise sob duas perspectivas. A primeira perspectiva é quanto ao diagnóstico, ou seja, se permite conhecer os pontos fortes e fracos da situação atual. A segunda é quanto ao aperfeiçoamento, ou seja, se permite a geração de ações de melhoria. Da primeira verificação resulta que 15 artigos realizaram o diagnóstico da situação atual, apresentando os pontos fortes e fracos do contexto (Figura 17). A segunda dimensão analisada mostrou que 10 artigos apresentam ações de melhoria, porém apenas cinco desenvolveram um processo para esse fim (Figura 18).

Figura 17 - Artigos do PB que fazem o diagnóstico da situação atual

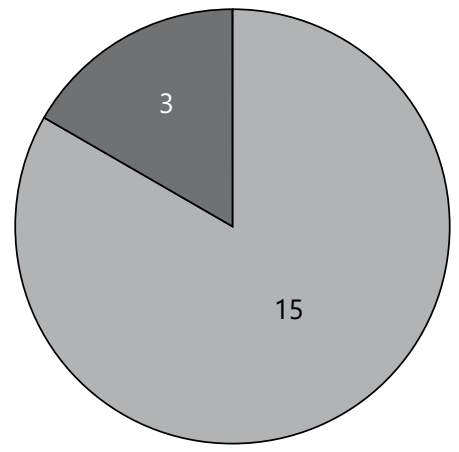

$\square$ Realiza o diagnóstico, identificando os pontos fortes e fracos do contexto.

$\square$ Não realiza o diagnóstico, não identificando os pontos fortes e fracos do contexto.

Fonte: Elaboração dos autores (2018) 
Figura 18 - Artigos do PB que geram ações de aperfeiçoamento

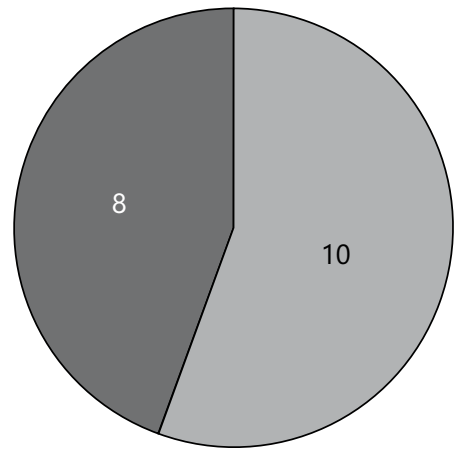

$\square$ Gera ações de aperfeiçoamento.

Não gera ações de aperfeiçoamento.

Fonte: Elaboração dos autores (2018)

\section{Considerações finais}

A partir da Análise Sistemática da Literatura realizada, utilizando o instrumento ProKnow-C, foi possível selecionar o fragmento da literatura que trata da avaliação de desempenho para o apoio à gestão de UO de Ifes, composto por 18 artigos. Da Análise Bibliométrica, verificou-se que os periódicos mais relevantes são Higher Education e Studies in Higher Education, que apresentam também os maiores Fatores de Impacto. $\mathrm{O}$ artigo mais relevante foi The development of HEdPERF: a new measuring instrument of service quality for the higher education sector, com 337 citações, e os autores mais expressivos foram Agasisti, T. e Johnes, G.

Da Análise Sistêmica, observou-se a opção preponderante dos autores pela utilização das abordagens realistas, com predominância da busca das variáveis no contexto físico e na literatura. A partir da análise da primeira lente, constatou-se que em nenhum artigo foi utilizada a abordagem construtivista, revelando uma lacuna de pesquisa. Apenas em sete artigos os decisores foram considerados para a seleção das variáveis, porém em apenas um de forma integral, e em nenhum artigo do PB houve a preocupação de gerar conhecimento para o decisor. Quanto ao processo de gestão, 10 artigos identificam ações de melhoria, porém apenas cinco apresentam um processo específico para este fim.

Desta análise, emerge como oportunidade de pesquisa a construção de um modelo de avaliação de desempenho que apoie à gestão de unidades organizacionais de universidades públicas, e que (i) utilize a abordagem construtivista harmonicamente ao uso/aplicação do modelo, (ii) que seja singular, identifique o decisor e considere suas preferências para a construção integral do modelo, (iii) oportunizando a 
geração de conhecimento no decisor através de um processo estruturado de identificação dos objetivos, (iv) utilizando escalas cardinais e ordinais compatíveis com a Teoria da Mensuração e suas propriedades, (v) permitindo a integração dos indicadores segundo as preferências do decisor a partir de níveis de referência e (vi) permitindo, ainda, gerar ações de melhoria por meio de processo estruturado, fornecendo desta forma embasamento ao decisor para demonstrar de que maneira deveria atuar para melhorar o desempenho no contexto avaliado.

Considera-se que uma limitação da presente pesquisa seja o número limitado de bases de dados utilizadas para o levantamento do $\mathrm{PB}$, pois não abrange todo $\mathrm{o}$ universo de trabalhos científicos. Como possibilidade de pesquisas futuras, a fim de ampliar o conhecimento sobre a temática de estudo, sugere-se a construção de um estudo de redes de colaboração entre os pesquisadores que compõem o banco de artigos brutos. Ressalta-se ainda que a análise sistêmica é realizada através de lentes que explicitam a afiliação teórica do pesquisador, que na presente pesquisa consistiu na avaliação de desempenho como instrumento de apoio à decisão. Desta forma, pode-se considerar como recomendações para novas pesquisas, a análise que adote outras abordagens, englobando aspectos da literatura não vislumbrados na presente pesquisa, como o enfoque no processo avaliativo formativo. 


\title{
Performance evaluation for supporting the management of organizational units in Ifes: Analysis and opportunities
}

\begin{abstract}
This study explores the literature related to performance evaluation to aid the management of organizational units of public universities, identifying future research opportunities. A Systematic Review of Literature was carried out through the Knowledge Development Process - Constructivist. The resulting Bibliographic Portfolio consisted of scientifically relevant articles, freely available and aligned with the research theme, after which bibliometric and systemic analyses were carried out. At the end of this process, we identify as a research gap, the construction of a performance evaluation model that supports the management of organizational units of public universities, using a constructivist approach, leading to the construction of knowledge in the decision maker, using ordinal and cardinal scales, performing the integration of the indicators based on the knowledge of the decision maker and presenting levels of reference, allowing the generation of improvement actions.
\end{abstract}

Keywords: Performance Evaluation. Public university. Systematic Review of Literature. ProKnow-C.

\section{Evaluación de desempeño para el apoyo a la gestión de unidades organizativas en Ifes: análisis y oportunidades}

\section{Resumen}

Este estudio explora la literatura sobre evaluación de desempeño para apoyar la gestión de unidades organizativas de universidades públicas, identificando oportunidades para futuras investigaciones. En este contexto, se realizó una Revisión Sistemática de la Literatura utilizando el instrumento Knowledge Development Process - Constructivist. Se seleccionó el Portafolio Bibliográfico de artículos cientificamente relevantes, se dispuso y alineó con el tema de investigación, y posteriormente se realizaron análisis bibliométricos y sistémicos. Al final de este proceso, se identifica como una brecha de investigación la construcción de un modelo de evaluación de desempeño que apoye la gestión de las unidades organizativas de las universidades públicas, utilizando el enfoque constructivista, conduciendo a la construcción del conocimiento en el tomador de decisiones, utilizando escalas ordinales y cardinal, integrando los indicadores del conocimiento del tomador de decisiones y presentando niveles de referencia, permitiendo acciones de mejora.

Palabras clave: Evaluación de Desempeño. Universidad Pública. Revisión Sistemática de la Literatura. ProKnow-C. 


\section{Referências}

ABDULLAH, F. The development of HEdPERF: a new measuring instrument of service quality for the higher education sector. International Journal of Consumer Studies, Oxford, v. 30, n. 6, p. 569-581, Nov. 2006. https://doi.org/10.1111/j.1470-6431.2005.00480.x

ABRUCIO, F. L. Trajetória recente da gestão pública brasileira: um balanço crítico e a renovação da agenda de reformas. Revista de Administração Pública, Rio de Janeiro, v. 41, n. esp, p. 67-86, 2007. https://doi.org/10.1590/S0034-76122007000700005

AGASISTI, T.; BONOMI, F. Benchmarking universities' efficiency indicators in the presence of internal heterogeneity. Studies in Higher Education, [s. 1.], v. 39, n. 7 , p. 1237-1255, 2014. https://doi.org/10.1080/03075079.2013.801423

AGASISTI, T.; JOHNES, G. Beyond frontiers: comparing the efficiency of higher education decision-making units across more than one country. Education Economics, v. 17, n. 1, p. 59-79, 2009. https://doi.org/10.1080/09645290701523291

AGASISTI, T.; JOHNES, G. Efficiency, costs, rankings and heterogeneity: the case of US higher education. Studies in Higher Education, [s. 1.], v. 40, n. 1, p. 60-82, 2015. https:// doi.org/10.1080/03075079.2013.818644

ALMEIDA, D. R., et al. Gerencialismo: efeitos no modelo de gestão em uma IFES. In: COLOQUIO INTERNACIONAL DE GESTIÓN UNIVERSTITARIA, 16., 2016, Arequipa, Peru, 2016. [S. n. t.].

ANDRIOLA, W. B.; ARAÚJO, A. C. Uso de indicadores para diagnóstico situacional de Instituições de Ensino Superior. Ensaio: Avaliação e Politicas Públicas em Educação, Rio de Janeiro, v. 26, n. 100, p. 645-663, jul./set. 2018. https://doi.org/10.1590/s0104-40362018002601062

ARAÚJO, M. A. D.; PINHEIRO, H. D. Reforma gerencial do Estado e rebatimentos no Sistema educacional: um exame do REUNI. Ensaio: Avaliação e Políticas Públicas em Educação, Rio de Janeiro, v. 18, n. 69, p. 647-668, out./dez. 2010. https://doi.org/10.1590/S0104-40362010000400002

BRASIL. Ministério do Planejamento, Desenvolvimento e Gestão. PEP - Painel Estatístico de Pessoal. Brasília, DF, 2020. Disponível em: http://painel.pep.planejamento.gov.br/QvAJAXZfc/opendoc. $\mathrm{htm}$ ?document $=$ painelpep.qvw\&lang=en-US\&host=Local\&anonymous=true $\%$ E2\%80\%8B. Acesso em: 27 mar. 2020. 
DOBIJA, D., et al. Rational and symbolic uses of performance measurement: experiences from Polish universities. Accounting, Auditing \& Accountability Journal, Bingley, v. 32, n. 3, p. 750-781, 2019. https://doi.org/10.1108/AAAJ-08-2017-3106

DUTRA, A., et al. The construction of knowledge from the scientific literature about the theme seaport performance evaluation. International Journal of Productivity and Performance Management, [s. 1.], v. 64, n. 2, p. 243-269, 2015. https://doi.org/10.1108/IJPPM-01-2014-0015

ENSSLIN, L., et al. Performance assessment model for bank client's services and business development process: a constructivist proposal. International Journal Applied Decision Sciences, [s. 1.], v. 11, n. 1, p. 100-126, 2018. https://doi.org/10.1504/IJADS.2018.088636

ENSSLIN, L., et al. Research process for selecting a theoretical framework and bibliometric analysis of a theme: illustration for the management of customer service in a bank. Modern Economy. v. 6, n. 6, p. 782-796, June 2015. https://doi.org/10.4236/me.2015.66074

ENSSLIN, L.; DUTRA A.; ENSSLIN, S. R. MCDA: a constructivist approach to the management of human resources at a governamental agency. International Transactions in Operational Research. v. 7, p. 79-100, 2000.

FAVERO, C. G. Avaliação de programas públicos: sistema de avaliação do Programa Nacional de Gestão Pública e Desburocratização aplicado na Marinha do Brasil: o caso do programa Netuno. Dissertação (Mestrado em Administração Pública) - Fundação Getúlio Vargas, Rio de Janeiro, RJ, Brasil, 2010.

FILGUEIRAS, F. A tolerância à corrupção no Brasil: uma antinomia entre normas morais e prática social. Revista Opinião Pública. Campinas, v. 15, n. 2, p. 386-421, nov. 2009. https://doi.org/10.1590/S0104-62762009000200005

GUERRA, M. F.; BRITO, A. C.; SOARES, J. L. Avaliação de desempenho das instituições de ensino superior brasileiras: uma reflexão à luz da controladoria. Revista Espacios, Caracas, v. 38, n. 15, p. 11-22, 2017.

KÖKSAL, G.; NALÇACI, B. The relative efficiency of departments at a Turkish engineering college: a data envelopment analysis. Higher Education, [s. 1.], v. 51, p. 173-189, 2006. https://doi.org/10.1007/s10734-004-6380-y 
KUZU, O. H. Strategy selection in the Universities via Fuzzy AHP Method: a case study. International Journal of Higher Education, [s..], v. 9, n. 2, p. 107-117, 2020. https://doi.org/10.5430/ijhe.v9n2p107

LUZ, T. A., et al. Performance evaluation of information technology servisse: the state of the art recognition by a constructivist research process and bibliometrics. Perspectivas em Ciência da Informação, Belo Horizonte, v. 21, n. 2, p. 120-140, abr./jun. 2016. https://doi.org/10.1590/1981-5344/2526

MACHORRO, F.; ROMERO, M. V. Propuesta de un instrumento de autoevaluación del desempeño organizacional en instituciones públicas de educación superior en México. Formación Universitaria, La Serena, v. 10, n. 3, p. 3-10, 2017. http://dx.doi.org/10.4067/S0718-50062017000300002

MARRA, A.V.; MELO, M. C.O. L. A prática social de gerentes universitários em uma instituição pública. Revista de Administração Contemporânea, Curitiba, v. 9, n. 3, p. 9-31, jul./set. 2005. https://doi.org/10.1590/S1415-65552005000300002

MCCORMACK, J.; PROPPER, C.; SMITH, S. Herding cats? Management and university performance. The Economic Journal, London, v. 124, n. 578, p. 534-564, 2014. https://doi.org/10.1111/ecoj.12105

MOLLIS, M.; MARGINSON, S. The assessment of universities in Argentina and Australia: between autonomy and heteronomy. Higher Education, [s. 1.], v. 43, p. 311-330, 2002. https://doi.org/10.1023/A:1014603823622

MORENO, A. A.; TADEPALLI, R. Assessing academic department efficiency at a public university. Managerial and Decision Economics, [s. 1.], v. 23, n. 7, p. 385-397, Oct./Nov. 2002.

MOTTA, P. R. M. O estado da arte da gestão pública. Revista de Administração de Empresas, São Paulo, v. 53, n. 1, p. 82-90, jan./fev. 2013. https://doi.org/10.1590/S0034-75902013000100008

ÖZDEMIR, A.; TÜYSÜZ, F. An integrated Fuzzy DEMATEL and Fuzzy ANP based Balanced Scorecard approach: application in Turkish higher education institutions. Journal of Multiple-Valued Logic \& Soft Computing, [s. 1.], v. 28, n. 2-3, p. 251-287, 2015.

PEREIRA, C. A.; PEREIRA, N. S. P.; MONTEIRO, R. P. Mapeamento conceitual do Balanced Scorecard no ensino superior. Revista Capital Científico - Eletrônica. Guarapuava, v. 13, n. 3, p. 10-27, 2015. https://doi.org/10.5935/2177-4153.20150019 
PLACEK, M.; OCHRANA, F.; PUCEK, M. Benchmarking in Czech higher education: the case of schools of economics. Journal of Higher Education Policy and Management, [s. 1.], v. 37, n. 4, p. 374-384, 2015. https://doi.org/10.1080/1360080X.2015.1056601

ROESCH, S. M. A. Projetos de estágio e de pesquisa em administração. 3a ed. São Paulo: Atlas, 2005.

ROSA, M. J.; SARAIVA, P. M.; DIZ, H. Defining strategic and excellence bases for the development of Portuguese higher education. European Journal of Education, [s. 1.], v. 40, n. 2, p. 205-221, 2005. https://doi.org/10.1111/j.1465-3435.2005.00220.x

SANTOS, L.P.G. Uma contribuição à discussão sobre a avaliação de desempenho das Instituições de Ensino Superior: uma abordagem da gestão econômica. Revista Contabilidade \& Finanças, São Paulo, v. 13, n. 28, p. 86-99, 2002. https://doi.org/10.1590/S1519-70772002000100006

SANTOS, R. N. M.; ELIEL, R. A.; ELIEL, O. A ciência e o novo estado do conhecimento: a contribuição da ciência da informação. Encontros Bibli - Revista Eletrônica de Biblioteconomia e Ciências da Informação, Florianópolis, v. 11, n. 22, p. 16-29, 2006. https://doi.org/10.5007/1518-2924.2006v11n22p16

TASCA, J.E. A contribuição da avaliação de desempenho, como um instrumento de apoio à decisão, para a prevenção ao crime baseada no ambiente. Tese (Doutorado em Engenharia de Produção). Universidade Federal de Santa Catarina - UFSC, Florianópolis, Brasil, 2013.

TASCA, J. E., et al. An approach for selecting a theoretical framework for the evaluation of training programs. Journal of European Industrial Training, [s. 1.], v. 34, n. 7, p. 631-655, 2010. https://doi.org/10.1108/03090591011070761

UMASHANKAR, V.; DUTTA, K. Balanced scorecards in managing higher education institutions: an Indian perspective. International Journal of Educational Management, [s. 1.], v. 21, n. 1, p.5 4-67, 2007. https://doi.org/10.1108/09513540710716821

VALMORBIDA, S.M.I. Avaliação de desempenho como instrumento de apoio ao gerenciamento da Diretoria de Planejamento e Administração de uma Universidade Pública Federal: uma perspectiva multicritério. Dissertação (Mestrado em Contabilidade). Universidade Federal de Santa Catarina UFSC, Florianópolis, 2012. 
YOUSIF, M.K.; SHAOUT, A. Fuzzy logic computacional model for performance evaluation of Sudanese Universities and academic staff. Journal of King Saud University - Computer and Information Sciences, v. 30, n. 1, p. 80-119, Jan. 2018. https://doi.org/10.1016/j.jksuci.2016.08.002

ZUNIGA-JARA,S., et al. Midiendo la creación de valor en una Universidad. Formación Universitaria, La Serena, v. 11, n. 3, p. 87-96, 2018. https://doi.org/10.4067/S0718-50062018000300087

\section{Informações sobre os autores}

Tatiane Roldão Bastos: Doutoranda em Modelagem Computacional pela Universidade Federal do Rio Grande. Técnica Administrativa em Educação pela mesma universidade. Contato: tatianeng@gmail.com

(iD) https://orcid.org/0000-0002-9367-9301

André Andrade Longaray: Doutor em Engenharia de Produção pela Universidade Federal de Santa Catarina. Professor do Instituto de Ciências Econômicas, Administrativas e Contábeis da Universidade Federal do Rio Grande. Contato: andrelongaray@gmail.com

iD https://orcid.org/0000-0002-2908-9390

Aléssio Bessa Sarquis: Doutor em Administração pela Universidade de São Paulo. Professor do Departamento de Ciências Sociais Aplicadas da Universidade do Sul de Santa Catarina. Contato: alessio.sarquis@gmail.com

iD https://orcid.org/0000-0001-9690-0510

Vilmar Antonio Gonçalves Tondolo: Doutor em Administração pela Universidade do Vale do Rio dos Sinos. Professor da Faculdade de Administração e Turismo da Universidade Federal de Pelotas. Contato: vtondolo@gmail.com

iD https://orcid.org/0000-0002-3116-2585 